\title{
The Use of Gamification in Higher Education: An Empirical Study
}

\author{
István Varannai \\ Department of Information \\ Technology \\ University of Miskolc \\ Miskolc, Hungary
}

\author{
Peter Sasvari \\ Institute of E-Government \\ National University of Public \\ Service \\ Budapest, Hungary
}

\author{
Anna Urbanovics \\ Faculty of International and \\ European Studies \\ National University of Public \\ Service \\ Budapest, Hungary
}

\begin{abstract}
The use of gamification in higher education has increased considerably over the past decades. An empirical study was conducted in Hungary with two groups of students to investigate their behaviour while interacting with Kahoot! The results were analyzed based on the technology acceptance model. They indicate that the positive attitude, good experience and ease of availability contributed to improve student performance which strengthened the intention to use the application. Besides these, the perceived utility was positively influenced by the ease of use as consequence.
\end{abstract}

Keywords-Gamification; education; Hungary; technology acceptance model; university student

\section{INTRODUCTION}

Gamification has increased considerably over the past decades as video games have become more colorful and lifelike. Immediate interaction between the users and establishment of a rewarding system helped gamification become widespread in higher education. However several definitions of gamification have spread simultaniously, the most accurate is Deterting's definition. It identifies gamification as the design, implementation and use of game mechanics in nongame contexts [11]. This definition was used in the research because it fits to the set targets. The research was conducted among two groups of university students, IT and non-IT students, in order to measure the impact of gamification in higher education. In general, we can observe a growing demand for gamified applications which can be explained mainly by the potential of gamification to engage and motivate students during lectures [12]. The target of the research was to analyze the experience of IT and non-IT students concerning the method of gamification by filling out a survey in the Evasys online sytem. The preliminary condition was to get familiar with the Kahoot! application which was introduced to the students by one of the university lecturers. This application created competition during lectures and enhanced group learning. Students could get feedbacks on their results so a rewarding- punitive system was formed. Different external and internal factors of motivation came to the fore while playing with Kahoot! Affective feedbacks were influenced by the application as it put well defined targets in front of the players. Generally stating, gamification engages

This paper has been written with the support of the National University of Public Service in the framework of the priority project KÖFOP-2.1.2VEKOP-15-2016-00001 titled „Public Service Development for Establishing Good Governance - Ludovika Digital Governance Research Group students to learn and enhance the development of positive learning attitudes [13]. The article aims to provide an overview of different factors of gamification and crawl correlations between them. The research is based on Davis's TAM model (technology acceptance model) of which main components are: use, utility, experience, attitude, intention and availability [2], [4]. Besides this, the article describes the possibilities of implementing gamification into higher education. The article is based on data of students of the University of Miskolc and the National University of Public Service.

First of all, we carry out a literature review and present the primary research and the Kahoot! application. In the remainder of this paper, we outline the research process and theoretical model used for the research. Finally, the discussion and summary of the results are given.

\section{LITERATURE REVIEW}

For the initial phase of the research, a literature review was done. The main focus was on the domain of education and science in general. The keywords were searched on databases related to the subject, including ScienceDirect and Scopus. The literature search revealed that the term gamification has spread steadily from 2010 internationally. While in 2011 only 15 documents were uploaded in the topic, it has extended almost 40 times by 2016 with 592 volumes. Altogether, in this period 1660 volumes were uploaded from 89 countries.

The research methodology is based on an article written by Maican, even though this article focuses on the comparison of different game-based application. With respect to the questionnaire and results it is a unique research [6].

\section{PRIMARY RESEARCH IN THE TOPIC}

The target group of the research is the $\mathrm{Z}$ generation whose members were born between 1995 and 2010, so they actually form the majority of the university students. Given the characteristics of this generation, it is supposed that participating in a "gamified" lecture would not be difficult to them. Members of this age-group have already been born to a digitalized world so the smart tools make part of their everyday routine. Internet and online games are popular among them, but they are opened to adapt new technologies as well. Because of these, following Marc Prensky's definition they are called "digital natives" [9]. They have a different way of thinking 
compared to members of the previous generations as they get access to information faster. Their learning habits have changed as well. Ar regards to their communication, they spend a couple of hours online every day, so they get used to contact virtually with each other. We can observe that the frequency of Internet access depends on the age. From younger age groups to elder people, not only the proportion of Internet users but also the intensity of use within the users decreases. This means that among the elderly there are less internet users, and that the elder internet users use internet less than youth [8]. $90 \%$ of the members of $\mathrm{Z}$ generation are online every day, while only a small group say, they use Internet once a month at most or not at all. Fig. 1 shows the Internet usage patterns among the $\mathrm{Z}$ generation.

The birth of $\mathrm{Z}$ generation into a digital and technology oriented world creates a number of problems in the field of education as well because the teaching methods of the 20th century are not successful and efficient enough anymore. Introduction of gamification could provide a solution for the difficulties of education systems with respect to the digital natives. They are perfectly familiar with the conditions of the gamification technology and they use it as a part of their daily routine.

\section{A. Our Research Tool: Kahoot!}

We can observe multiple advantages of gamification in every field of life. Loyalty schemes give us the best examples. They are built up on this method, where the more you purchase, the more points you score and the higher reductions you get in case of the next shopping [7]. Customers are motivated to earn points to reach higher levels with higher reductions (e.g. bronze, silver, gold and platina level customers of telecommunication companies, or reductions for several frequent flyers of airways). With reference to the Nike, with its Nike+ application we can measure our results at running, our development in the sport, and even compete with others virtually while we can receive different prizes or video messages from famous athletes. The company could increase its income with $10 \%$ from the running stocks last year due to this gamified project [1]. Other example is the application of the Nissan Leaf's $100 \%$ electronic car where we can count the number of virtual trees which we can increase by driving energy efficiently. Altogether, we can see many creative and successful examples for gamified projects. We can observe gamification at language-teaching soft wares (e.g. Duolingo), or the Hungarian- developed gamified innovative e-learning systems (BeeTheBest, Redmenta). It can be stated that gamification motivates people to learn more using these applications, however only a few articles have been written about its impact on learning. In the research the Kahoot! application was used to measure this impact. We can observe a general competition between the players because the main aim is to skip always to higher level. Kahoot! uses competition as a motivating factor as well. Besides the web-based platforms, the application runs perfectly on tablets and mobile phones and the mobile application is available for both Andriod and Ios users. The following simplified flowchart (Fig. 2) provides an overview on how the Kahoot! works (prior registration needed).

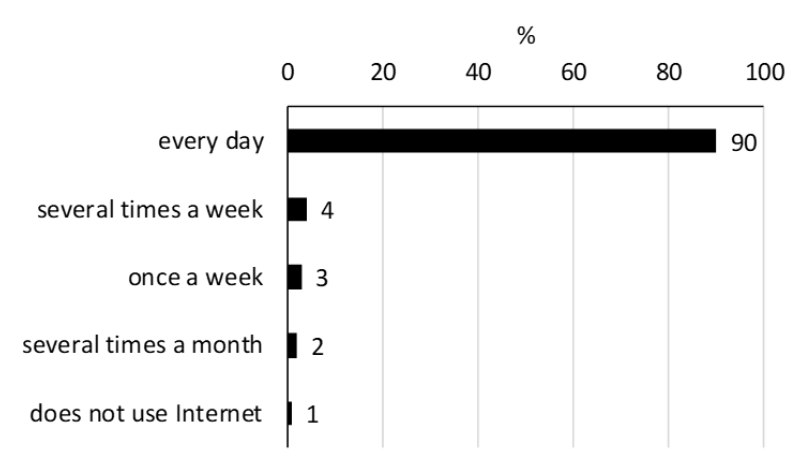

Fig. 1. Frequency of Internet use by the $\mathrm{Z}$ generation (Among telecommunication services and public users, based on 2016).

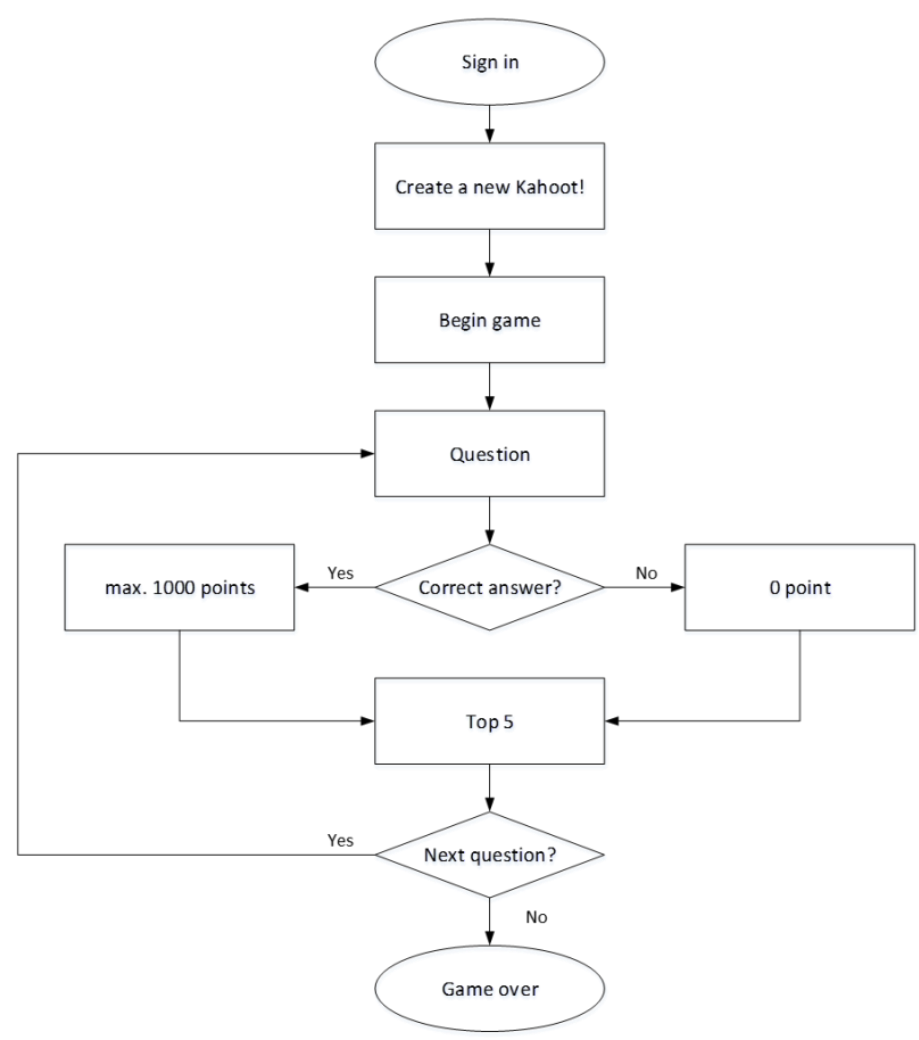

Fig. 2. Simplified flow diagram of the Kahoot! application.

After logging in we can prepare quizzes, but we also have the possibility to play with games which were prepared by others. In order to be more colorful, we can add different images and videos to our quiz. When playing only the internet access must be granted and a notebook is also necessary to screen the questions because they are not visible on the players' own devices. During the 2016/17 fall semester 1000 points could be scored for every right answer and 0 points for wrong ones. The points are also influenced by the reaction time so the faster you answer the more points you score from the total 1000. After responding each question, the top five players are displayed. If the game has not finished, the next question appears on the main screen. When the game is over, the lecturer can download the final results in an Excel spreadsheet, 
or can synchronize them to a Google Drive profile. Students $\log$ in using their Neptun code (unique identifier), so the players' list can be used as an attendance list as well. On the left side of the question we can find the remaining time, while on the right the number of received answers is presented. Students could participate in the competition once a week at the end of each lecture. The questions were linked always to the actual topic. They got 5-6 questions every week so the game was not too long but the high-level of motivation could be observed through the semester due to the awards. It can be observed that by the Kahoot! a balance between the internal and external motivation was found.

\section{THEORETICAL MODELLING}

In parallel with the increasing technological requirements the expectations grow. In order to reach the best quality, and satisfy every expectation several concepts have been developed which are called as quality measuring models and systems. They can be used to estimate future success or to eliminate potential faults. Their common feature is that they take into account the human element. The doctoral thesis of Davis in 1989 was written as a result of this process, which served to examine the link between the motivation and system characteristic. It is called the TAM, Technology Acceptance Model. The model consists of different motivation factors, and most importantly it is based on human attitude. Elements of the TAM model can be divided into subjective and objective elements. The subjective elements are e.g. the user acceptance and behaviour, while the objective elements are more measurable e.g. the use. According to the model, use of the new technology is defined by the cognitive (impacts of cognition) and the affective (emotional impacts) feedbacks as it is mentioned in Fig. 3.

Based on Fig. 3 it appears that technology acceptance has two determinants: the use should be simple and the recognized benefit should be high [6] [13]. The easier the use is, the higher the recognized benefit will be. From the user's aspect technology acceptance depends on elements such as the simple adaption of technology and the perceived help of technology. These elements are parts of external motivation [5]. Besides these, technology acceptance depends on widespread motivation factors, such as the personal enjoyment. However, the supporting commitment is influenced largely by the external factors [3]. One of these can be the personal environment which influences the acceptance to a great extent. The contrary of this can occur also, as someone's environment can be influencing concerning the term and intensity of use [10].

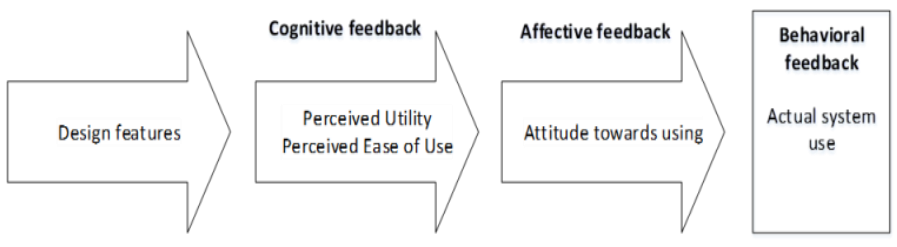

Fig. 3. Technology acceptance model [2].

\section{A. Assumptions}

The research is based on elements of the TAM model, so the aim was to examine links between these elements in the study as Fig. 4 indicates:

- Utility: shows how the user evaluates the usage of the system, if they concern it adequate.

- Use: shows how the user evaluates the complexity of the system.

- Experience: shows what impacts the usage of system generates in the user.

- Availability: shows to what extent the user is satisfied with the system concerning its accessibility.

- Attitude: shows the willingness of the user to accept and use the system in case of continual use.

- Intention: shows how the user relates to the future usage of the system.

Based on the model outlined and these elements, the relation between them can be supposed as follows:

- H1: There is a positive correlation between utility and attitude to the game.

- H2: There is a positive correlation between availability and attitude.

- H3: There is a positive correlation between experience and attitude.

- H4: There is a positive correlation between experience and intention for future usage.

- H5: There is a positive correlation between availability and attitude.

- H6: There is a positive correlation between availability and intention.

- H7: There is a positive correlation between use and utility.

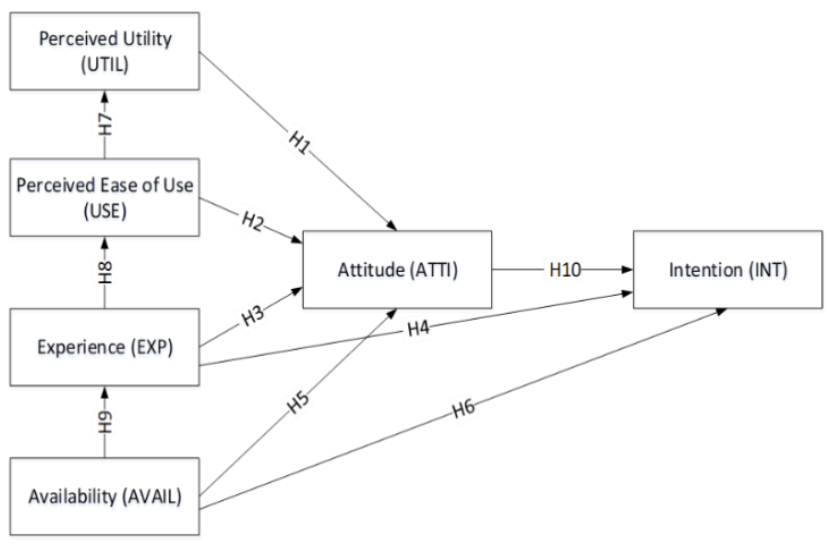

Fig. 4. Applied research model (based on Davis [2]). 
H8: There is a positive correlation between experience and use.

H9: There is a positive correlation between availability and experience.

H10: There is a positive correlation between attitude and intention.

\section{RESEARCH PROCESS}

Both primary and secondary research was carried out. In the course of the secondary research several publications from international databases were used. Based on these authentic and reliable data the primary research could be determined. After setting the aims and assumptions, a questionnaire was carried out as well. Students of The University of Miskolc and of The National University of Public Service participated in the survey. They could access to the questionnaire through the online Evasys system, on the webpage of evasys.unimiskolc.hu. After reaching enough number of samples results were processed by the IBM SPSS Statistics 23 statistical software package. The questionnaire was formed based on the preliminary assumptions. Each question is dedicated to one hypothesis. In the survey only students using Kahoot! regularly could take part because the questions were connected with the application. Altogether, 86 samples were taken from non-IT students of The National University of Public Service and IT students of The University of Miskolc. The target group was the $\mathrm{Z}$ generation (shown coloured black in Fig. 5), the distribution of respondents by age is included in Fig. 5 .

Fig. 6 shows the number of samples received from the university departments.

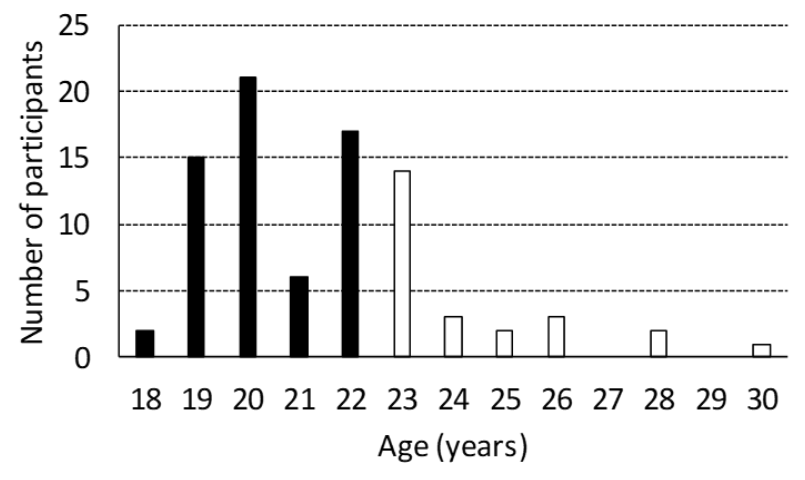

Fig. 5. Distribution of participation by age.
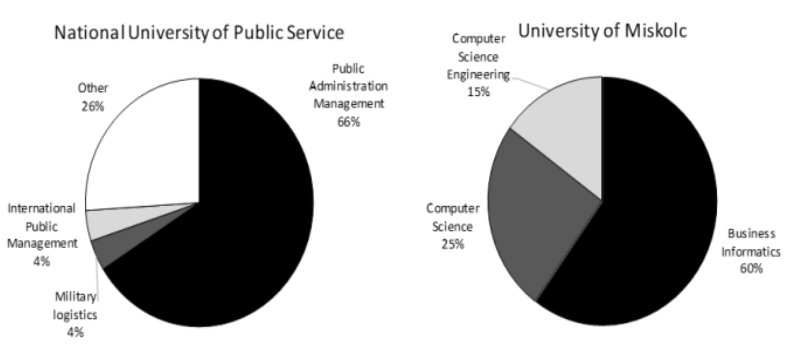

Fig. 6. Number of participants by university department.
Non-IT students of the National University of Public Service give the $59,3 \%$ of the samples, and the IT students of the University of Miskolc give 40, 7\%. Examining the samples in terms of the breakdown by gender, it can be observed that nearly 50-50 percent completed the questionnaire. $47 \%$ of the samples were taken from men, and 53\% from women.

\section{ANALytical Results Among UniVERSity StUdENTS}

\section{A. Factor Analysis}

After completing the descriptive statistical analysis of the data, the examination was continued with the principal component method which is a widely used method of factor extraction. First of all, in order to decide whether the data are appropriate for factor analysis it was essential to check their nature by KMO and Bartlett-test. The aim of the principal component analysis is to extract the maximum possible variance with successive factoring continuing until there is no further meaningful variance left. By the KMO (Kaiser-MeyerOlkin) criterion we can decide whether our data are appropriate for factor analysis. The higher its value is, the more appropriate the variants are.

- $\mathrm{KMO} \geqslant 0,5$ the data are suitable for factor analysis.

- $\mathrm{KMO}<0,5$ the data are not suitable for factor analysis.

Besides the appropriate value of the KMO, another criterion is to have correlation between the two variants which we can check with the Bartlett-test.

- H0: there is no correlation between the variants.

- H1: the variants are in correlation with each other.

After the examination of the test's results the H0 assumption could be ruled out both in case of IT and non-IT students because we can observe a correlation between the variants $(\mathrm{p}=0.000$, see Table 1$)$, so they are suitable for factor analysis. The KMO value regarding the IT-students is 0.702 (see Table 1), while regarding the non-IT students it is 0.696 (see Table 1), so the variants are suitable for carrying out a factor analysis.

Having said that the variants are suitable for factor analysis, as a next step it was necessary to examine how many factors would be appropriate to be created. This appropriate number is 5 as it is included in the following two charts.

TABLE I. RESUlts OF THE KAISER-MEYER-OKLIN (KMO) TEST AND BARTLETT-TEST AMONG IT AND NON-IT STUDENTS

\begin{tabular}{|l|l|l|}
\hline & IT students & Non-IT students \\
\hline $\begin{array}{l}\text { Kaiser-Meyer-Olkin (KMO) } \\
\text { Test }\end{array}$ & 0.702 & 0.696 \\
\hline Bartlett's Test significance & 0.000 & 0.000 \\
\hline
\end{tabular}


The Kaiser-criterion provides that only those factors which eigenvalue is not less than 1 have to be taken into account, because, in particular, it alleges that if the eigenvalue fall below 1, it carries negligible information, so it would become pointless to examine the data. When defining the factor number a further criterion is that the aggregated variant rate percentage must be $60 \%$, in other words, the factors must contain at least $60 \%$ of the original information. If the 17 variants would be included into 5 factors it would contain $73.743 \%$ of the original information so we would obtain 12 variants with around $26.3 \%$ of the loss of information. These values can be easily calculated from the eigenvalues, as the explained variant percentage is the given eigenvalue's rate to all component numbers, and the cumulative percentage shows how many percentages of all variants can be explained when examining the given factor with the preceding factor's variant. The principal component analysis was carried out for non-IT students as well. It can be seen that both at the case of IT and non-IT students the principal component analysis created 5 groups, what's more it doesn't classify all of the questions to the group where the original expectations lay, however these 5 groups seem to be an insufficient number because the questions were divided into 6 categories before, so for the 5 factors are not suitable. Based on these we can assume that it's not practical to create more than 5 categories, so it was essential to check the original structure of 6 categories with the maximum likelihood estimation. The factor number shows the initial number of items, in other words the 17 factors. It appears that the slope of factors is steadily decreasing regarding at the examined categories. Searching for the "elbow point"- in other words the point where the slope breaks and start turn into horizontal-it's easy to see that the factor numbers can be maximized in 6 categories as well. The elbow detection technique entails that the factors which eigenvalues are below 1 can be important also in the course of an analysis. Having completed the previous statistical analyses, the variants could be divided into 6 categories - as mentioned above. So it became possible name the elements of the model as follows: As each element was asked in different ways the categorization simplified the following calculations.

\section{B. Test-Retest Reliability}

One of the most important questions when evaluating a survey is the reliability of the data. Most simply put, the aim of this test was to measure to what extent our survey makes precise calculation. The value of Cronbach's alpha is between 0 and 1 , where the 1 shows the most reliability and the 0 the least reliability data. If the Cronbach's alpha $>0.7$ the test can be considered reliable. Examining the test among IT students, this value is 0.798 , while the same can be said about the test among non-IT students where the value of the alpha is 0.775 as the following table (Table 2) shows it. Both values proved to be reliable.

TABLE II. RESULTS OF THE RELIABILITY TESTING

\begin{tabular}{|l|l|l|}
\hline Category & Cronbach's alpha & Number of questions \\
\hline IT students & 0.798 & 17 \\
\hline Non-IT students & 0.775 & 17 \\
\hline
\end{tabular}

\section{Summary of the Results}

Concerning the IT-students, we can observe a positive correlation at the level of $1 \%$ significance concerning $\mathrm{H} 4$ (Experience and Intention) and H9 (Availability and Experience). There is a positive correlation at the level of 5\% significance in case of H10 (Attitude and Intention) and H7 (Easy Use and Utility), besides these the positive correlation regarding $\mathrm{H} 8$ (Experience and Easy Use) at the level of $10 \%$ significance is verified as well. The correlation values are indicated in Fig. 7.

Based on the results of non-IT students we can observe a positive correlation at the case of $\mathrm{H} 4$ (Experience and Intention) and $\mathrm{H} 10$ (Attitude and Intention) at the level of $1 \%$ significance. A positive correlation at the level of $5 \%$ significance can also be verified concerning the H1 (Utility and Attitude), H5 (Availability and Attitude) and H9 (Availability and Experience). Besides these, at the level of $10 \%$ significance positive correlation appears at H7 (Easy Use and Utility) and H6 (Availability and Intention). On the contrary, the $\mathrm{H} 2$ assumption (Easy Use and Attitude) was contradicted, because the two variables show negative correlation instead of the expected positive correlation. As a summary, four assumptions can be observed which were verified both at the case of IT and non-IT students. Based on the results, it can be said that the intention is always influenced by the attitude and experience which, at the same time, strongly depends on the availability of the application (here the Kahoot!). Both categorization shows that the easy use influences positively the perception of utility. The results are summarized in Table 3.

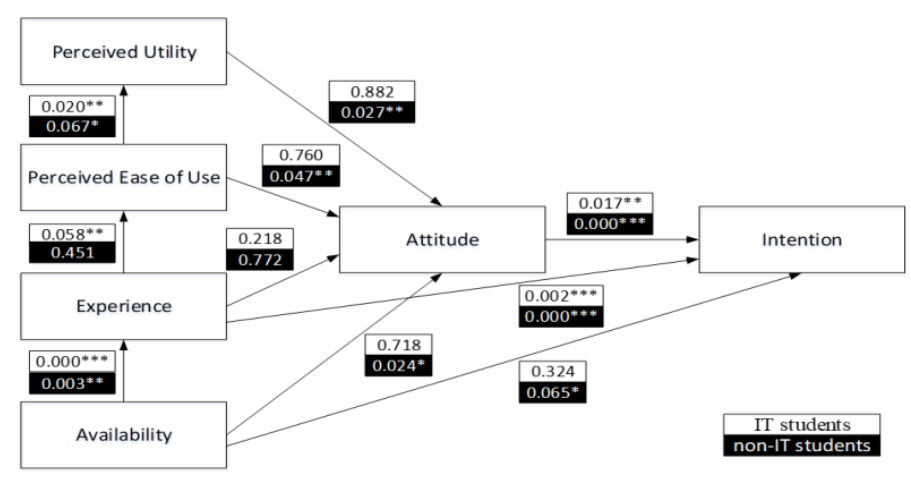

Fig. 7. Correlation between the elements of the model regarding IT students and non-IT students $* \rho<0.1, * * \rho<0.05, * * * \rho<0.01$ ).

TABLE III. SUMMARY OF THE RESULTS OF HYPOTHESIS TESTING

\begin{tabular}{|l|l|l|}
\hline \multirow{2}{*}{ Hypothesis } & Verified & Non-IT students \\
\cline { 2 - 3 } & IT students & yes \\
\hline H1 & no & no \\
\hline H2 & no & no \\
\hline H3 & no & yes \\
\hline H4 & yes & yes \\
\hline H5 & no & yes \\
\hline H6 & no & yes \\
\hline H7 & yes & no \\
\hline H8 & yes & yes \\
\hline H9 & yes & yes \\
\hline H10 & yes & \\
\hline
\end{tabular}


We can observe significant differences between the IT and non-IT students. The attitude of non-IT students are typically influenced by the utility and availability. There is a difference concerning the $\mathrm{H} 6$ hypothesis also because the future intention is influenced by the availability. Regarding the IT students, their attitude does not depend on the utility and availability, and their intention is not influenced by the availability. This can be explained by the fact that these students are much closer to the technologies of gamification, so due to their openness to new technologies no correlations could be identified between the availability of the application and their future intention to use the Kahoot!

\section{SUMMARY}

The use of gamification is still a sensitive subject of the Hungarian education system these days. A long time has passed by the time the lecturers established the point of view that instead of the traditional educational culture they involve a more modern method to pass on the knowledge and meanwhile the generation that needed this has grown up - based on the research results. In view of the low number of literatures found in this topic, during the work several publications could be found from foreign authors in different scientific databases. Based on these we brought back the concept of gamification and built it up enough to be used in the Hungarian higher education. Following the formation of the definition as well as separation of conceptual items different factors were determined which influence the road that leads to the success of gamification. On the other hand, the confirmation or refutation of hypothesis that were set up based on the TAM model became essential. The method consisted of the preparation of a questionnaire and then its statistical evaluation. 86 bachelor students answered the 20 questions that were asked in the EvaSys system. The first three complex questions of the survey were followed by 17 five degree Likert Scale questions. All the scalable questions were asking about one of our hypotheses. The conclusion is that the IT and nonIT students look at the use of gamification differently. Out of the 10 hypotheses only 5 were backed up with the IT students, meanwhile in the group of the non-IT students, 7 of our assumptions were verified. Based on the research results we can observe that students in certain IT classes didn't find the lectures immersive where the use of gamification was applied. The reason for this could be that part of their every day is formed by tools similar to some gamified lectures. This is backed up by the fact that most IT students used mobile applications to connect to the game. With respect to non-IT students gamification had clear success, however the assumption that the simple use of the game influences the approach to the game in a positive way, was refuted. The hypothesis that states there is a positive relationship between the simple use of experience and the detected was also refuted. We can come to the conclusion that the experience of the game does not influence the subjective quality of the application which determines how easy or hard it is to use. Based on the results summarized in the dissertation, gamification could propose a solution for the most serious problem of higher education, namely, the phenomenon that at the beginning of the semester students visit lectures and seminars actively but by the end of the semester - if there is no binding attendance list the headcount decreases significantly.

\section{REFERENCES}

[1] H. Chen, W. Rong, X. Ma, Y. Qu, Z. Xiong, “An Extended Technology Acceptance Model for Mobile Social Gaming Service Popularity Analysis", Mobile Information Systems, vol. 2017, pp. 1-12, 2017.

[2] F. D. Davis, "Perceived Usefulness, Perceived Ease of Use, and User Acceptance of Information Technology", MIS Quarterly, Vol. 13, No. 3 (Sep., 1989), pp. 319-340, 1989.

[3] P. Isaias, T. Issa, "High Level Models and Methodologies for Information Systems", Springer-Verlag New York, 2015.

[4] G. Kim, D. Choe, J. Lee, S. Park, S. Jun, D. Jang, "The Technology Acceptance Model for Playing Console Game in Korea", IJCSNS, International Journal of Computer Science and Network Security, vol. 13, pp. 9-12, December 2013.

[5] J. McGonigal, "Reality is Broken: Why games make us better and how they can change the world", Penguin Books; 2011.

[6] C. Maican, R. Lixandroiu, C. Constantin, Interactivia.ro e A study of a gamification framework using zero-cost tools, Computers in Human Behavior, vol. 61, pp. 186-197, 2016.

[7] N. Merkovity, A. Nemeslaki, "eLearning developments in Public Services - Editorial Preface”, Információs Társadalom, vol. 14, Issue: 1, pp. 5-8, 2014.

[8] K. Nesterowicz, A. Neacsu, SM Fereshtehnejad, A. Nemeslaki, "Exploring the acceptance of e-learning in continuing pharmacy education", Pharmacy Education, vol. 16, Issue: 1, pp. 33-37, 2016.

[9] M. Prensky, "Digital Natives, Digital Immigrants", On the Horizon, vol. 9, pp. 1-6, October 2001.

[10] K. L. Ritter, "Gamification: How will Service Management 'play along'?", Finalist and 3rd Place winner in the itSMF International Whitepaper Submission Competition 2012.

[11] B. U. Stetina, O. D. Kothgassner, M. Lehenbauer, I. Kryspin-Exner, "Beyond the fascination of online-games: Probing addictive behavior and depression in the world of online-gaming", Computers in Human Behavior, vol. 27, pp. 473-479, January 2011.

[12] B. C. de Souza, L. X. de L. e Silva, A. Roazzi, "MMORPGS and cognitive performance: A study with 1280 Brazilian high school students", Computers in Human Behavior, vol. 26, pp. 1564-1573, November 2010.

[13] E. Wästlund, H. Reinikkaa, T. Norlandera, T. Archerb, "Effects of VDT and paper presentation on consumption and production of information: psychological and physiological factors", vol. 21, pp. 377-394, March 2005. 